\title{
“CÍRCULO DE CULTURA” FREIREANO: ESPAÇO DIALÓGICO DE ENSINO, PESQUISA E EXTENSÃO
}

\author{
FREIREAN “CULTURAL CIRCLE”: DIALOGICAL SPACE OF \\ TEACHING, RESEARCH AND EXTENSION
}

\author{
Rosária Helena Ruiz Nakashima ${ }^{1}$ \\ Karolina Martins Almeida e Silva ${ }^{2}$ \\ Matheus Pereira Lobo ${ }^{3}$
}

\section{RESUMO}

O legado de Paulo Freire inspira ações para o ensino, a pesquisa e a extensão nas universidades e escolas públicas brasileiras. Neste artigo, discutimos as contribuições do "círculo de cultura" sobre a vida e as obras freireanas a partir de uma dinâmica de reciprocidade de conhecimentos e experiências, fundamentadas na problematização e na sua pedagogia libertadora. Observamos o envolvimento dos participantes no movimento dialético (teoria e prática) na reflexão de suas próprias ações pedagógicas, a partir de "palavras-geradoras".

Palavras-chave: Legado freireano; Palavras-geradoras; Educação libertadora.

\section{ABSTRACT}

Paulo Freire's legacy inspires actions for teaching, research and extension in Brazilian universities and public schools. In this article, we discuss the contributions of the "circle of culture" on Freirean life and works based on a dynamic of knowledge and experiences reciprocity, based on problematization and its liberating pedagogy. We observe the participants involvement in the dialectical movement (theory and practice) in the reflection of their own pedagogical actions, from "generating words".

Keywords: Freirean legacy. Generating words. Liberating education.

\footnotetext{
${ }^{1}$ Doutora em Educação pela Faculdade de Educação da USP. Docente da Universidade Federal do Tocantins Campus Araguaína. rosaria@uft.edu.br.

${ }^{2}$ Doutora em Educação pela Faculdade de Educação da UnB. Docente da Universidade Federal do Tocantins Campus Araguaína.karolinaeducabio@gmail.com.

${ }^{3}$ Doutor em Física Teórica (Unesp). Docente da Universidade Federal do Tocantins - Campus Araguaína. mplobo@uft.edu.br.
} 


\section{nesiste

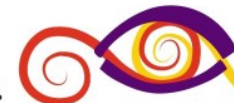 \\ Debates Insubmissos}

\section{INTRODUÇÃO}

A educação é um fenômeno multidimensional e complexo, envolvendo diferentes sujeitos em diversos contextos sociais, como crianças e jovens em situação de risco social, mulheres, negros, indígenas, quilombolas, homossexuais entre outros. Paulo Freire é um autor mundialmente conhecido pela vitalidade do seu pensamento e, por participar de lutas em defesa de uma educação para todos e todas, ao definir que seu "ponto de vista é o dos 'condenados da Terra', o dos excluídos" (FREIRE, 2015, p. 16), constrói uma filosofia educacional para e com os oprimidos.

Considerando o legado freireano como uma fonte de inspiração para a permanente construção de uma educação libertadora e democrática, em 2017, foi realizado um colóquio ${ }^{4}$ para lembrar os vinte anos de seu falecimento, em 02/05/1997. O objetivo principal foi destacar seu legado para a realização de ações de ensino, pesquisa e extensão, ou seja, o principal tripé das universidades públicas brasileiras. Assim, esse evento interdisciplinar contou com mesas-redondas e um "círculo de cultura" para promover estudos de suas obras, bem como o aprofundamento de conceitos freireanos.

Neste artigo, destacamos as contribuições do momento "círculo de cultura", realizado durante esse evento extensionista, envolvendo acadêmicos e docentes da graduação e da pósgraduação, representantes da diretoria regional de ensino da cidade de Araguaína, professores das redes públicas e privadas do município e da região, além de membros da comunidade em geral. No prefácio da obra "Pedagogia do Oprimido", o professor Ernani Maria Fiori explica que:

No círculo de cultura, a rigor, não se ensina, aprende-se em "reciprocidade de consciências"; não há professor, há um coordenador, que tem por função dar as informações solicitadas pelos respectivos participantes e propiciar as condições favoráveis à dinâmica do grupo, reduzindo ao mínimo sua intervenção direta no curso do diálogo. (FREIRE, 2017, p. 15).

Neste trabalho, apresentamos as contribuições do "círculo de cultura", como um espaço dinâmico e dialógico, no qual os participantes puderam conhecer as principais

\footnotetext{
4 I Colóquio Paulo Freire: Ensinar exige a convicção de que a mudança é possível. Realizado na Universidade Federal do Tocantins, Campus de Araguaína, nos dias 8 e 9 de maio de 2017.
} 
informações da vida e de obras de Freire, bem como trocar conhecimentos e experiências educacionais a partir de "palavras-geradoras", fundamentadas na pedagogia libertadora e problematizadora freireana.

\section{METODOLOGIA}

A Resolução CNE/CP n 2, de $1^{\circ}$ de julho de 2015. (BRASIL, 2015) ao apresentar as Diretrizes Curriculares Nacionais para a formação inicial em nível superior (cursos de licenciatura, cursos de formação pedagógica para graduados e cursos de segunda licenciatura) e para a formação continuada, destaca a importância da articulação do ensino, da pesquisa com a extensão. Nesse sentido, o "I Colóquio Paulo Freire: Ensinar exige a convicção de que a mudança é possível” buscou fazer essa integração, especialmente durante a realização do "círculo de cultura".

Utilizamos como ferramenta didático-pedagógica o vídeo-documentário "Paulo Freire Contemporâneo", com o objetivo de evidenciar aspectos relativos à vida e obra de Paulo Freire. Esse documentário de 53 minutos foi dirigido por Toni Venturi e produzido pela TV Escola no ano de 2006. A principal estratégia foi apresentar aos participantes do "círculo de cultura" elementos fundamentais do pensamento freireano, articulando sua vida e seu legado bibliográfico a partir de aspectos de sua infância, formação profissional e política. $\mathrm{O}$ documentário foi construído com base em depoimentos de familiares, educadores de vários países e intelectuais, e ainda apresentou experiências de escolas que adotam o legado pedagógico de Paulo Freire.

Frente ao objetivo do "círculo de cultura" em propiciar aos participantes da oficina uma compreensão sobre a construção histórica do pensamento pedagógico de Freire e incitar discussões sobre sua pedagogia libertadora e problematizadora, no contexto educativo contemporâneo, a oficina foi desenvolvida em três momentos principais: 1) exibição do vídeo-documentário; 2) organização de grupos para discussão e elaboração de cartazes; e 3) socialização.

No primeiro momento, os participantes foram orientados a assistirem o documentário e anotarem aspectos significativos para serem discutidos posteriormente. Após a exposição do 


\section{Revista (O) \\ Debates Insubmissos}

documentário, os participantes foram organizados em grupos de até dez pessoas. Foram formados sete grupos. Cada grupo recebeu um envelope com trinta "palavras-geradoras" que foram elaboradas pelos organizadores da oficina a partir do estudo sobre o vídeodocumentário trabalhado.

A entrega das palavras aos grupos foi delineada a partir de uma proposta didática que visou propor aos participantes uma compreensão do legado de Paulo Freire, apresentado no vídeo-documentário, e relacioná-las com as vivências e interpretações dos participantes a partir de sua realidade social. Nesse sentido, utilizamos como "palavras-geradoras": libertadora; liberdade; pedagogia; oprimido; opressor; aprendizagem; tema gerador; problematização; curiosidade epistemológica; humanístico; dentre outras.

No segundo momento, os participantes se reuniram e receberam folhas de papel pardo, cola, pincéis coloridos e os envelopes contendo as palavras para organizarem suas interpretações de forma livre. Finalmente, no momento da socialização, buscamos valorizar as interpretações dos grupos e identificar as relações elaboradas pelos participantes. A integração dos acadêmicos, da comunidade em geral, dos professores universitários e da educação básica pública resultou em um trabalho enriquecedor, com trocas de experiências e saberes fundamentais para a educação contemporânea.

\section{RESULTADOS}

Paulo Freire construiu uma filosofia da educação a partir da visão de que a educação deve ser, antes de tudo, um instrumento para a libertação e emancipação das pessoas. Para Freire (2015, p. 77),

A mudança do mundo implica a dialetização entre a denúncia da situação desumanizante e o anúncio de sua superação, no fundo, o nosso sonho. É a partir deste saber fundamental: mudar é difícil, mas é possível, que vamos programar nossa ação político-pedagógica [...].

Durante o "círculo de cultura", cada grupo discutiu o significado das "palavrasgeradoras" freireanas e a relação entre elas, apresentada no cartaz produzido, inspirou cada grupo na socialização de como essas palavras contribuíram para a reflexão sobre a educação, em diferentes contextos. Os títulos dos três capítulos do livro "Pedagogia da Autonomia" se 
transformaram nas categorias para analisarmos essas reflexões: a) Não há docência sem discência ${ }^{5}$; b) Ensinar não é transferir conhecimento e c) Ensinar é uma especificidade humana.

\subsection{Não há docência sem discência}

Freire anuncia no subtítulo da obra "Pedagogia da Autonomia" a sua temática central, ou seja, o livro trata dos "saberes necessários à prática educativa". A prática em questão visa à autonomia dos educandos em contextos educativo-progressistas. Freire retoma, nesta obra, temáticas abordadas em outros livros, reaproximando-se de questões relevantes "num movimento de procura, que rediscuto a curiosidade ingênua e a crítica, virando curiosidade epistemológica" (FREIRE, 2015, p. 16).

Nesse mesmo movimento, observamos que dois grupos se aproximaram das discussões que Freire fez nas seções do capítulo 1 de "Pedagogia da Autonomia", ou seja, "Não há docência sem discência". Esse título sugere que professores e estudantes são igualmente importantes no desenvolvimento da prática educativo-crítica e destaca que "a reflexão crítica sobre a prática se torna uma exigência da relação Teoria/Prática sem a qual a teoria pode ir virando blá-blá-blá e a prática, ativismo". Nesse processo, professores e estudantes aprendem e ensinam uns aos outros, a partir de suas diferentes experiências, isto é:

Quando vivemos a autenticidade exigida pela prática de ensinar-aprender, participamos de uma experiência total, diretiva, política, ideológica, gnosiológica, pedagógica, estética e ética, em que a boniteza deve achar-se de mãos dadas com a decência e com a seriedade. (FREIRE, 2015, p. 26).

Durante o "círculo de cultura", no momento da socialização, o grupo A, formado por professoras da rede pública de Araguaína e região, ressaltou, em sua apresentação, a integração das "palavras-geradoras": transformação, escola e coletividade. Para elas, a escola é um espaço capaz de promover a transformação dos estudantes, instrumentalizando-os para

\footnotetext{
5 Na sexta edição (1996) o primeiro capítulo foi nomeado como "Não há docência sem discência", posteriormente, houve uma mudança para "Prática docente: primeira reflexão". Neste trabalho, optamos pelo título anterior.
} 
modificar suas realidades. Ressaltaram a força da coletividade para que essas transformações possam ser operacionalizadas nas práticas pedagógicas. Sobre isso, para Freire (2015, p. 42):

[...] uma das tarefas mais importantes da prática educativo-crítica é propiciar as condições em que os educandos em suas relações uns com os outros e todos com o professor ou a professora ensaiam a experiência profunda de assumir-se. Assumir-se como ser social e histórico, como ser pensante, comunicante, transformador, criador, realizador de sonhos [...].

Essas ideias freireanas também inspiraram o grupo $\mathrm{F}$, formado por acadêmicas da UFT e professoras da rede pública, a destacarem as seguintes "palavras-geradoras": pedagogia do oprimido, pensamento crítico e transformação.

Esse grupo relembrou a importância da obra "Pedagogia do Oprimido", traduzida em 17 idiomas, tornando-se mundialmente conhecida. Escrito em 1968, a obra foi proibida pela ditadura militar e só em 1974 chegou ao Brasil. Esse livro expressou o resultado das atividades educativas e reflexões feitas por Freire, durante os cinco anos que permaneceu exilado em Santiago do Chile.

O grupo F destacou que essas três "palavras-geradoras" contribuem para a concretização de uma educação democrática, na qual o papel docente não é apenas ensinar conteúdos curriculares, mas também ensinar a pensar criticamente, como sujeitos históricos ativos que, ao conhecer o mundo, fazem questionamentos e podem transformar suas realidades sociais. Para isso, o grupo enfatizou a importância do professor se reconhecer também como pesquisador, pois

\begin{abstract}
Não há ensino sem pesquisa e pesquisa sem ensino. Esses quefazeres se encontram um no corpo do outro. Enquanto ensino, continuo buscando, reprocurando. Ensino porque busco, porque indaguei, porque indago e me indago. Pesquiso para constatar, constatando, intervenho, intervindo educo e me educo. Pesquiso para conhecer o que ainda não conheço e comunicar ou anunciar a novidade. (FREIRE, 2015, p. 30-31).
\end{abstract}

Freire salientou a relação do ensino e da pesquisa com a ideia de "curiosidade epistemológica", ou seja, o professor deve respeitar e partir do saber ingênuo do estudante, mas promover espaços para que a ingenuidade se transforme em pensamento crítico, assumindo-se como seres sociais, históricos e criadores.

\title{
3.2 Ensinar não é transferir conhecimento
}




\section{Revista \\ Debates Insubmissos}

No segundo capítulo do livro "Pedagogia da Autonomia", Freire (2015, p. 47) destaca que "ensinar não é transferir conhecimento, mas criar as possibilidades para a sua própria produção ou a sua construção". Nesse sentido, o grupo C, formado por professores do ensino superior, educação básica e membro da comunidade, destacou as seguintes "palavrasgeradoras": problematização, diálogo e inacabamento.

A partir de suas diferentes vivências, o grupo destacou que, tanto no ensino superior como na educação básica, os professores devem atuar como educadores problematizadores, que transformam suas aulas em espaços para questionar "as verdades", com disponibilidade para dialogar e negociar a realização de práticas pedagógicas, de acordo com as demandas, ideias e interesses dos estudantes. Para isso, é fundamental a "consciência do inacabamento", porque "onde há vida, há inacabamento" (Ibidem, p. 50).

O grupo C ressaltou que o futuro não está predeterminado, ou seja, por sermos sujeitos históricos podemos promover transformações e Freire ressalta que esse é um compromisso de todo educador. Além disso, anuncia que:

Gosto de ser gente porque, mesmo sabendo que as condições materiais, econômicas, sociais e políticas, culturais e ideológicas em que nos achamos geram quase sempre barreiras de difícil superação para o cumprimento de nossa tarefa histórica de mudar o mundo, sei que os obstáculos não se eternizam. (Ibidem, p. 53).

O grupo $\mathrm{D}$, formado por acadêmica da pós-graduação, professores universitários e da educação básica, ressaltou as "palavras-geradoras": amor, esperança e identidade cultural. Relembraram que a filosofia freireana envolve o respeito aos saberes dos educandos e a rejeição de qualquer forma de discriminação.

Como estamos na região Norte do Brasil, o grupo mencionou a importância da escola valorizar os saberes dos quilombolas, indígenas, quebradeiras de coco babaçu, barqueiros e demais culturas tradicionais do estado do Tocantins. O diálogo que aproxima as mais variadas experiências dos estudantes com os saberes escolares é capaz de construir "pontes" para que o conhecimento aprendido seja significativo e pertinente para as comunidades onde eles vivem. Mas, para isso o professor deve conhecer esses contextos e promover essas relações. Nessa perspectiva, Freire (2015, p. 66) nos apresenta um questionamento, "como ser educador, se não desenvolvo em mim a indispensável amorosidade aos educandos com quem me 


\section{novistet

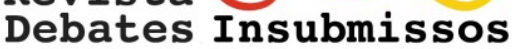

comprometo e ao próprio processo formador de que sou parte?". Assim, além das competências técnico-científicas, o professor também deve alimentar a amorosidade no desenvolvimento de suas ações pedagógicas.

\subsection{Ensinar é uma especificidade humana}

As obras de Paulo Freire ainda são consideradas subversivas pelos opressores, pois denunciam os métodos de exclusão praticados pelas classes dominantes que defendem a "educação bancária", na qual os estudantes são compreendidos como sujeitos passivos, que "recebem" as informações narradas pelos professores, depositadas em suas mentes.

A narração, de que o educador é o sujeito, conduz os educandos à memorização mecânica do conteúdo narrado. Mais ainda, a narração os transforma em "vasilhas", em recipientes a serem "enchidos" pelo educador. Quanto mais vá "enchendo" os recipientes com seus "depósitos", tanto melhor o educador será. Quanto mais se deixem docilmente "encher", tanto melhores educandos serão. [...]

Em lugar de comunicar-se, o educador faz "comunicados" e depósitos que os educandos, meras incidências, recebem pacientemente, memorizam e repetem. (FREIRE, 2017, p. 80).

Nessa perspectiva, o grupo $\mathrm{G}$, formado por professores da rede pública e acadêmicos da pós-graduação, destacou as "palavras-geradoras": ditadura, justiça social e autonomia; e o grupo E, formado por professoras da rede pública, complementou com as expressões: golpe 64, exílio e educação bancária.

Os grupos relembraram a perseguição de Freire durante o regime militar (1964-1985) por ter desenvolvido uma filosofia educacional, voltada para a cultura popular, que conscientizava e politizava homens e mulheres excluídos do processo de alfabetização. De acordo com Scocuglia (1999, p. 8-9), Freire,

Nos anos 1960, em pleno vigor do populismo e do nacional-desenvolvimentismo, como integrante do Serviço de Extensão Cultural da Universidade do Recife, elaborou uma proposta de alfabetização para os adultos que partia do seu "universo vocabular" e do cotidiano de seus problemas, para gerar palavras, sons, sílabas, fonemas e, com elas, ensinar a ler e escrever em pouco tempo. Essa metodologia pretendia ser "rápida, moderna e barata" e, em 40 horas, alfabetizar os adultos que, assim, poderiam "ler melhor o mundo" e, inclusive, adquirir o direito de votar, de escolher (o que até pouco tempo foi vedado aos analfabetos). (...) Freire foi coordenar o Plano Nacional de Alfabetização (PNA) no final de 1963. Esse Plano previa a alfabetização "em massa" 


\title{
novist \\ Debates Insubmissos
}

de 5 a 6 milhões de brasileiros em 1964 através da formação de 20.000 "círculos de cultura".

Ao sentir que as posições da classe dominante, bem como seus privilégios estavam sendo ameaçados por essa filosofia educacional, "Freire ficou preso (IV Exército - Recife) durante 70 dias, exilando-se, a seguir. Sua volta foi permitida, com a "abertura" do Estado Militar, depois de quinze anos!” (SCOCUGLIA, 1999, p. 9).

Corroborando com as mesmas ideias dos grupos $\mathrm{G}$ e E, o grupo B destacou as "palavras-geradoras": libertação, ideologia, movimentos sociais. As diferentes experiências educacionais dos participantes lembraram que estamos vivendo em um momento políticoeducacional bastante delicado e trouxeram como exemplo o projeto de lei "Escola Sem Partido" (PL 7180/14) que propõe acrescentar tópicos à Lei de Diretrizes e Bases da Educação Nacional (LDB), 9394/96, e dispor sobre a conduta dos professores dentro de sala de aula. Para Frigotto (2016, p. 12),

\begin{abstract}
Ao pôr entre aspas a denominação de "Escola sem Partido" quer-se sublinhar que, ao contrário, trata-se da defesa, por seus arautos, da escola do partido absoluto e único: partido da intolerância com as diferentes ou antagônicas visões de mundo, de conhecimento, de educação, de justiça, de liberdade; partido, portanto da xenofobia nas suas diferentes facetas: de gênero, de etnia, da pobreza e dos pobres, etc. Um partido, portanto, que ameaça os fundamentos da liberdade e da democracia liberal, mesmo que nos seus marcos limitados e mais formais que reais. Um partido que dissemina o ódio, a intolerância e, no limite, conduz à eliminação do diferente.
\end{abstract}

Nessa perspectiva, os grupos problematizaram que há uma ideologia nesse projeto de lei que ameaça a liberdade e autonomia das escolas. Assim, reforçaram que o legado freireano é fundamental por nos lembrar da nossa responsabilidade como professores, comprometidos com o exercício do magistério como uma das formas de intervir no mundo, em favor da justiça, solidariedade e democracia.

\section{CONCLUSÃO}

O "círculo de cultura" realizado durante o "I Colóquio Paulo Freire: Ensinar exige a convicção de que a mudança é possível”, na Universidade Federal do Tocantins, Campus de Araguaína, foi um importante espaço dialógico de ensino, pesquisa e extensão. 
$\mathrm{Na}$ dimensão do ensino, observamos que todos se envolveram num movimento dialético (teoria e prática) para refletir sobre suas ações pedagógicas na educação básica e no ensino superior. No âmbito da extensão, os participantes destacaram a importância do "círculo de cultura" para promover a integração da universidade com a escola pública, bem como com membros da comunidade interessados em (re)conhecer o legado freireano para a educação amazônica. Este trabalho concretiza a dimensão da pesquisa, ao convidar os organizadores do "círculo de cultura" a sistematizarem e socializarem os resultados das discussões ocorridas nesse momento específico do Colóquio.

A partir do documentário e da discussão entre os membros dos grupos, a partir das "palavras-geradoras", foi possível criar espaços de reflexão e socialização sobre o legado de Paulo Freire. Essas palavras expressaram temáticas significativas freireanas que nos mobilizaram e nos fortaleceram na luta por educação gratuita, equitativa, solidária e humana. Esse "círculo de cultura" nos fez relembrar de que há muitos desafios na educação, mas que não basta denunciá-los, temos que anunciar as possibilidades para sua transformação. Isso não se faz cruzando os braços, como se não houvesse solução, mas sim com esperança, alegria, compromisso e responsabilidade com a nossa própria formação docente e com a dos nossos estudantes, convictos de que mudar é difícil, mas é possível!

\section{REFERÊNCIAS}

BRASIL. Resolução CNE/CP n. 2, de 2015. Define as Diretrizes Curriculares Nacionais para a formação inicial em nível superior (cursos de licenciatura, cursos de formação pedagógica para graduados e cursos de segunda licenciatura) e para a formação continuada. Diário Oficial da União, Brasília, 2 de julho de 2015 - Seção 1 - pp. 8-12.

FREIRE, Paulo. Pedagogia do Oprimido. 63.ed. Rio de Janeiro/São Paulo: Paz e Terra, 2017.

FREIRE, Paulo. Pedagogia da Autonomia: Saberes Necessários à Prática Educativa. 63.ed. Rio de Janeiro: Paz e Terra, 2015.

FRIGOTTO, Gaudêncio. "ESCOLA SEM PARTIDO”: IMPOSIÇÃO DA MORDAÇA AOS EDUCADORES. e-Mosaicos, [S.1.], v. 5, n. 9, p. 11 - 13, jul. 2016. 
Revista

Debates Insubmissos

SCOCUGLIA, Afonso Celso. O adeus e o legado de Paulo Freire. Revista de Educação. In.:_ . A História das Idéias de Paulo Freire e a atual crise de paradigmas. 2.ed. João Pessoa: Ed. Universitária / UFPB, 1999.

Submetido em: 19/12/2018

Aprovado em: 06/02/2019 